\title{
Imagem e estética na construção discursiva do popular: reflexões sobre duas telenovelas de João Emanuel Carneiro
}

\section{Image and aesthetics in the discursive construction of the popular: reflections on two João Emanuel Carneiro's telenovelas}

Rosana Mauro ${ }^{1}$ 


\section{Resumo}

\section{Palavras-chave}

Este artigo objetiva abordar a construção discursiva do popular do ponto de vista da imagem nas telenovelas de João Emanuel Carneiro, com a direção de Amora Mautner - Avenida Brasil (2012) e A regra do jogo (2015). O intuito é refletir sobre como o discurso popular é constituído pelo formato da telenovela, sua estrutura visual e materialidade. A observação de cenas sugere a existência de uma estética que relaciona o popular ao cotidiano, ao rotineiro e vulgar, colocando as necessidades do corpo em evidência. Tais aspectos apontam para um efeito de realidade que atualiza o caráter de representação de cotidiano da telenovela e dialoga com o real democrático discutido por Rancière (2010). O trabalho também apresenta a pertinência de um estudo que dialogue com as teorias do imaginário, como ampliação e complemento a uma análise discursiva.

Telenovela, popular, estética, imagem, cotidiano.

\section{Abstract}

This paper aims to approach the discursive construction of the popular from the point of view of the image in the telenovelas of João Emanuel Carneiro, with the direction of Amora Mautner - Avenida Brasil (2012) and $A$ regra do jogo (2015). The intention is to reflect on how popular discourse is constituted by the format of the telenovela, its visual structure and materiality. The observation of scenes suggests the existence of an aesthetic that relates the popular with everyday life, with the routine and ordinary life, putting the body needs in evidence. Such aspects point to a reality effect which updates the character of quotidian representation in the telenovela, connected with the democratic real discussed by Rancière (2010). The work also shows the relevance of considering the imaginary theories, such as extension and complement to a discursive analysis.

\section{Keywords}

Telenovela, popular, aesthetics, image, quotidian. 
As definições atribuídas, no dicionário (FIGUEIREDO, 1913), à palavra "popular" são: respeitante ou pertencente ao povo; próprio do povo; usado ou frequente entre o povo, vulgar; que se dirige ao povo, feito para o povo; promovido pelo povo; que agrada ao maior número de pessoas; que goza do favor público; democrático. Uma das atribuições da palavra povo, por sua vez, é: conjunto da maioria dos indivíduos de um país, por oposição às classes dirigentes ou às classes mais favorecidas material e culturalmente. Desse modo, tendo as definições do dicionário como base, empregamos a palavra "popular" neste artigo para se referir ao comum à maioria das pessoas que são menos favorecidas na sociedade em termos socioeconômicos. Ou seja, em um sentido de habitus de classe social (BOURDIEU, 2007).

A telenovela, embora seja um produto da cultura de massa, destinada a muitos, não necessariamente representa o povo menos favorecido. De acordo com Meyer, a base para o surgimento do folhetim televisivo foi o que ela denomina de folhetim de terceira fase, que retratava os costumes parisienses e os dramas cotidianos. O paradoxo desse folhetim era ser considerado popular e burguês ao mesmo tempo, pois propunha modelos burgueses de aspiração da vida. Esse tipo de romance retratava frequentemente a nobreza e a burguesia triunfante, "vistas pelo duplo prisma da ideologia desta e do deslumbramento da pequena classe média e das classes populares" (MEYER, 1996, p. 223).

De modo similar, a pesquisadora Esther Hamburger (1998) argumenta que as telenovelas difundem por todo o país o universo glamouroso de consumo das classes médias urbanas, entre outros aspectos, por meio do consumo de últimos lançamentos eletrônicos, de decoração e vestuário.

Apesar de haver escritores como Benedito Ruy Barbosa, que costuma discutir questões sociais em suas telenovelas desde a década de 1970, a representação das classes populares sempre esteve restrito, de modo geral, aos núcleos paralelos (SOUZA apud RONSINI, 2012). A partir de 2002, com o aumento 
da renda de uma parte da população², algumas produções culturais passaram a destacar as classes populares, como o que ocorreu com as telenovelas Senhora do Destino (2004, 2005) e Duas Caras (2007, 2008), ambas de Aguinaldo Silva (JUNQUEIRA, 2009). Posteriormente, as telenovelas Avenida Brasil (2012) cuja maior parte dos personagens era do subúrbio carioca - e Cheias de Charme (2012) - com o protagonismo das empregadas domésticas - se tornaram famosas na mídia por representarem a "nova classe C" (MAURO, 2014).

Além da questão da representação em termos de conteúdo, é importante atentar também à estética, estrutura, imagem e forma como constituintes do discurso popular. Conforme apontam Silva e Soares, criticar a mídia é fazer crítica cultural e, portanto: "temos que obrigatoriamente nos colocar dentro de uma discussão sobre estética e ética, forma e conteúdo, técnica e valor" (2013, p. 829).

Nesse sentido, em 1968, a telenovela Beto Rockfeller, transmitida na Tupi, representou um marco para um formato mais popular, com o uso de linguagem coloquial, ênfase em cenários contemporâneos e brasileiros, com gravações externas (HAMBURGER, 1998).

Mais de 40 anos depois, na Rede Globo, Avenida Brasil (2012), de João Emanuel Carneiro, foi considerada um fenômeno midiático e um divisor de águas nas telenovelas (LOPES; MUNGIOLI, 2013). Do ponto de vista explorado neste artigo, a trama teve o diferencial de trazer às cenas diálogos sobrepostos e em voz alta, indicando mais informalidade e naturalidade nas falas dos personagens do subúrbio carioca, reproduzindo, de certa maneira, as conversas informais que permeiam nosso cotidiano. É possível sugerir que houve uma inovação na representação dos gêneros primários - da conversa informal e corriqueira de acordo com Bakhtin (2003) - justamente por se tratar de uma representação popular, da "nova classe C" brasileira, segundo notícias da época. 
Em A regra do jogo (2015), também de João Emanuel Carneiro, o recurso do diálogo informal parece se repetir em alguns núcleos dramáticos. Além disso, antes da estreia da telenovela, notícias anunciavam a utilização de "câmeras escondidas" nas gravações, segundo declarações da diretora Amora Mautner, a mesma de Avenida Brasil.

Sugere-se, assim, haver na parceria entre João Emanuel Carneiro e Amora Mautner uma "marca" estética na representação do popular, cuja abordagem requer um olhar voltado às especificidades da televisão, além do conteúdo. Para isso, faremos um breve retorno histórico ao folhetim escrito.

\section{"Olhar sem corpo"}

Martín-Barbero (2009), ao falar do folhetim impresso, aborda quatro níveis compostos por dispositivos importantes para seu universo cultural popular e massivo.

O primeiro nível é o dos dispositivos de composição tipográfica, caracterizada por letras grandes, claras e espacejadas, em decorrência de leitores que não estão habituados à leitura e/ou que não dispõem de iluminação adequada para fazê-la (MARTÍN-BARBERO, 2009, p. 185).

O segundo nível apresenta os dispositivos de fragmentação da leitura. As frases são fragmentadas, bem como o parágrafo e também os episódios são divididos em partes, capítulos e subcapítulos. Essa fragmentação torna a leitura leve e espaçada por dias ou semanas (MARTÍN-BARBERO, 2009, p. 186).

No terceiro nível estão os dispositivos de sedução, divididos em duração e suspense. A duração do folhetim é como a duração da vida. O leitor tem tempo para identificar-se com os personagens durante o tempo que dura a história. A duração do folhetim confunde-se com a duração da própria vida (MARTÍNBARBERO, 2009, p. 187). Já o suspense é buscado no fim de cada episódio e instiga a curiosidade do leitor.

No quarto nível se situam os dispositivos de reconhecimento, que produzem a identificação do mundo do leitor popular com o mundo narrado. 
Benjamin, em Paris, capital do século XIX (1985), faz uma analogia entre o panorama (grandes pinturas expostas publicamente, vistas por um grande número de pessoas) e o folhetim, referindo-se ao último como arte panoramática, na qual a poesia se submete à montagem e cujos personagens são compostos plasticamente assim como figuras no primeiro plano dos panoramas.

No folhetim eletrônico, é possível identificar características análogas, como a fragmentação em capítulos, o suspense, os ganchos, uma narrativa de fácil assimilação e também os personagens planos, embora haja aqueles mais complexos.

Um diferencial importante da teleficção em relação ao folhetim escrito é a linguagem icônica. O signo icônico, segundo a semiótica peirciana, é idêntico ao objeto que é representado (SANTAELLA, 2008). Na televisão, é como se a câmera fosse o narrador e as técnicas se apagassem.

Stam e Shohat (2006), ao abordarem a representação eurocêntrica no cinema, destacam o constante esquecimento das dimensões cinematográficas e da linguagem icônica quando é dada ênfase ao enredo e personagens. Segundo os autores, o discurso eurocêntrico no cinema pode se revelar na iluminação, na mise-en-scène, na música e no equilíbrio entre o primeiro plano e plano de fundo, por exemplo. "Uma análise abrangente deve dar atenção às 'mediações': a estrutura narrativa, as convenções do gênero, o estilo cinematográfico." (STAM; SHOHAT, 2006, p. 302)

Começaremos observando a tela. Podemos compará-la, por exemplo, com a concepção de molduras e/ou enquadramentos de Peñuela Cañizal (2013). O autor trata a moldura como um enquadramento configurador e escritural. "O enquadramento configurador é um componente escritural que tem sua origem na moldura ou armação que, durante séculos, vinha enquadrando as pinturas." (PEÑUELA CAÑIZAL, 2013, p. 105)

O enquadramento é parte de uma necessidade humana, segundo ele, de "prender" algo que ainda não é apreensível pela linguagem, como o próprio 
ambiente em transformação. "Há sempre o desejo de tornar visível o invisível: trazer até o alcance dos olhos espectros de algo que precede a linguagem, de algo que se une à agitação recôndita e obscura instalada nas fendas das coisas elementares do universo" (PEÑUELA CAÑIZAL, 2013, p. 98).

De forma similar, Soares (2001) faz uma analogia entre moldura e tela. Essa relação entre o dentro e fora de uma moldura, explica a autora, inclui algo trazendo para dentro, mas ao demarcar contornos exclui alguma outra coisa. Do mesmo modo, Xavier (2003, p. 32), ao versar sobre a fotografia e o cinema, expõe a relevância de chamar a atenção para a moldura, diante da "fé na imagem", para a questão do visível e invisível da qual brota o sentido.

O autor explica que há o encontro da câmera com o objeto e o encontro do espectador com o aparato de projeção. Existe todo um processo entre esses dois instantes, apagado no momento do encontro com o aparato (a tela, no caso da teleficção). O espectador, ao se pôr no lugar do aparato, adquire um olhar privilegiado, ultrapassa a barreira física, temporal e espacial do olho humano, se posiciona no centro da cena, sem participar dela. Xavier chama esse olhar de "olhar sem corpo", ubíquo e onividente.

Na sala escura, identificado com o movimento do olhar da câmera, eu me represento como sujeito dessa percepção total, capaz de doar sentido às coisas, sobrevoar as aparências, fazer a síntese do mundo. Minha emoção está com os "fatos" que o olhar segue, mas a condição desse envolvimento é eu me colocar no lugar do aparato, sintonizado com suas operações. (XAVIER, 2003, p. 48)

Embora o foco do autor esteja no cinema, suas colocações são válidas para a televisão e para a telenovela, em específico. No caso desta, temos a história se desenrolando em nossa frente, muitas vezes, na sala de nossas casas. São detalhes cotidianos, em cenários domésticos, figurinos e hábitos dos personagens que se estendem por meses, tempo suficiente para o "olhar sem corpo", que se coloca no lugar do aparato, adquirir intimidade com os personagens ao observálos por diferentes ângulos. 
Em Avenida Brasil, por exemplo, eram recorrentes cenas ambientadas na sala de jantar na mansão do personagem Tufão, iniciadas com um plano aberto com ângulo alto, no qual a câmera captava a mesa toda de jantar, os integrantes da família sentados, a decoração do local e, às vezes, uma empregada em pé próxima à mesa. Posteriormente, a câmera fechava nos personagens que conversavam, mas com um enquadramento capaz de capturar os objetos de decoração atrás da mesa e sobre ela.

O plano aberto, nesse caso, manifesta a pretensa formalidade do ritual alimentar da família, pretensa porque, ao nos aproximarmos, com o fechamento de câmera, observa-se o comportamento relaxado de alguns, o exagero e o exotismo dos objetos de decoração, conotando certa inadequação da família, que enriqueceu repentinamente, ao gosto estético de uma classe socioeconômica elevada. É importante ressaltar que o enquadramento que capta os objetos exerce um papel favorável na sua publicidade, visto que estes são procurados pelos telespectadores/consumidores pela Central Globo de Atendimento ao Telespectador (CAT) e alguns são vendidos pela Globo Marcas.

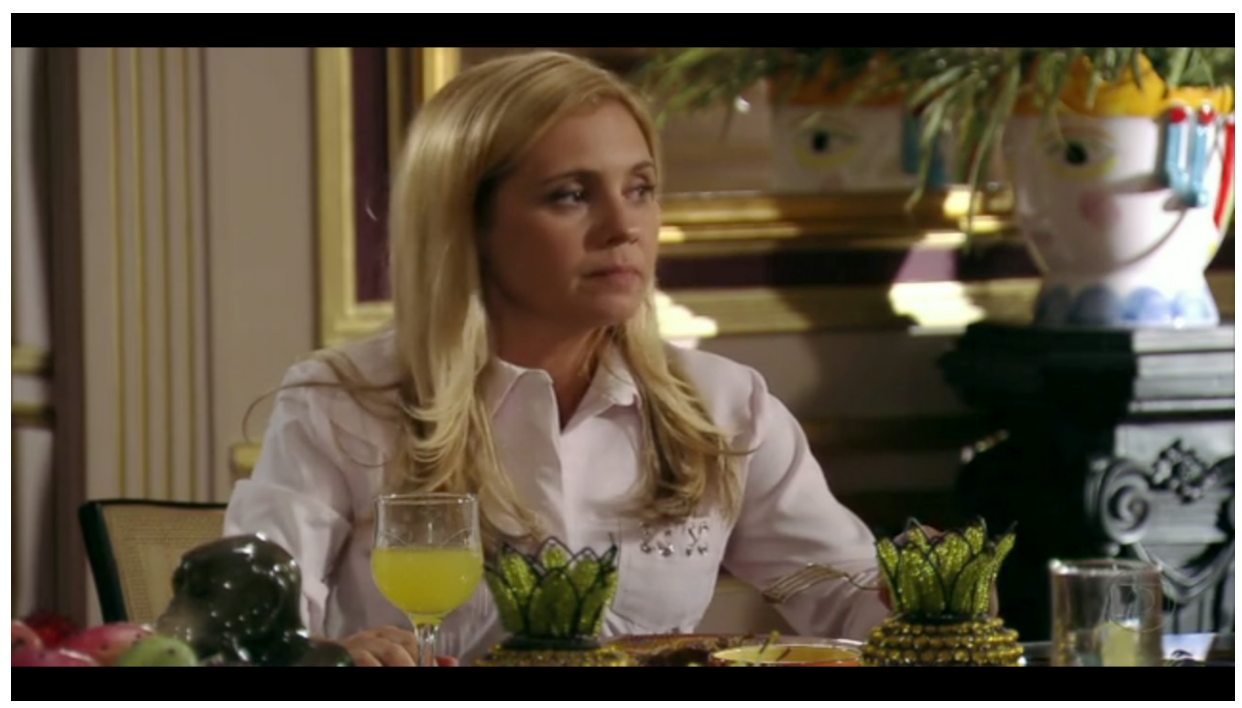

Figura 1: Detalhes do vaso atrás da personagem e os ornamentos na mesa

Fonte: http://gshow.globo.com/novelas/avenida-brasil/capitulo/ 2012/4/5/ivana-apresenta-carminha-a-nina.html 
Também em Avenida Brasil, havia enquadramentos que se assemelhavam ao ponto de vista de uma câmera escondida, ressaltando a impressão de onividência por parte do telespectador. Por exemplo, em uma cena em que a personagem Nina conversa com Lucinda em um bar do subúrbio carioca, bastante simples, temos o ponto de vista inicial de quem as espia, com um plano aberto distante e ângulo baixo. O telespectador parece estar agachado, escondido, o que é reforçado por alguns papéis soltos que se colocam em frente da câmera, dando a impressão de um olhar natural, improvisado.

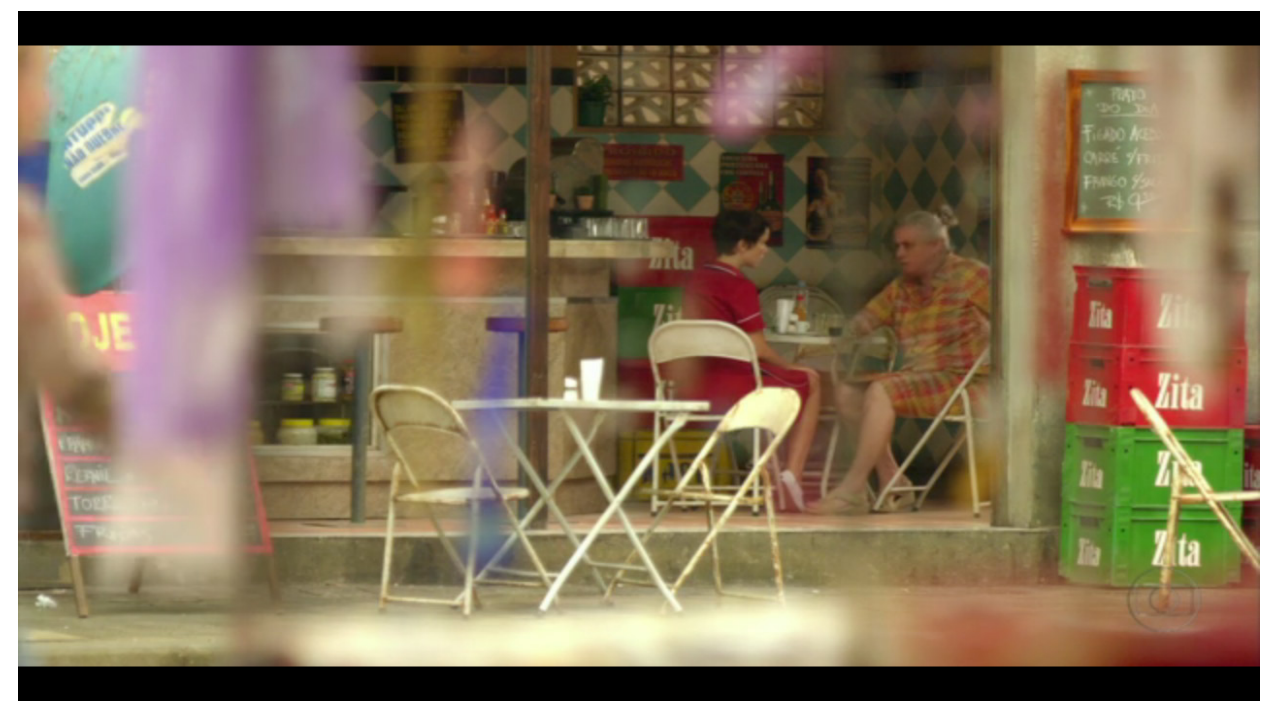

Figura 2: Avenida Brasil, ponto de vista como se o telespectador espiasse a cena Fonte: http://gshow.globo.com/novelas/avenida-brasil/capitulo/ 2012/4/7/nina-descobre-que-jorginho-e-batata.html

A regra do jogo (2015), por sua vez, como mencionado, utiliza o recurso de câmeras escondidas e estúdio circular para atuações mais naturais, inspiradas na estética dos realities shows. São oito câmeras; duas são robôs, cuja localização os atores desconhecem. Algumas ficam escondidas atrás de espelhos ou dentro de armários ${ }^{3}$. 
O intuito de alcançar o efeito de atuações mais naturais, e talvez mais "reais", com estratégias de gravação ou como os diálogos sobrepostos de Avenida Brasil, supõe-se, atualiza a representação do cotidiano na telenovela e se aproxima mais de uma estética popular. A palavra "atualiza" é empregada para expor que a representação do cotidiano sempre existiu na telenovela, mas que essas duas tramas proporcionam novos aspectos a ela.

\section{Cotidiano e efeito de realidade}

De acordo com Motter (2003), a representação do cotidiano na telenovela prende os personagens no tempo e no espaço, e traz, assim, realidade à trama. Entre outros elementos, o cenário permite a construção dessa cotidianidade. A permanência do mesmo cenário confere aos personagens um modo de habitar, de ser, assim como o que eles consomem tem igual função. A cotidianidade é construída em interação com o ambiente.

Em Avenida Brasil, as cenas da família de Tufão ao redor da mesa tiveram destaque, nas quais os integrantes da família falavam alto sobre assuntos triviais, e combinavam cerveja com os pratos sofisticados da cozinheira Nina, por exemplo. Também a personagem Monalisa foi representada frequentemente em um cenário doméstico, preparando alimentos em sua cozinha.

Do mesmo modo, a família de Feliciano em $A$ regra do jogo é exibida, muitas vezes, reunida em volta da mesa, ou no sofá da casa, na ampla cobertura (que não conseguem mais manter), discutindo assuntos de família, intimidades e problemas financeiros.

A refeição em família desempenha um papel importante na telenovela, de modo geral, mas nos núcleos populares representa uma oportunidade de mostrar os costumes dos personagens, com momentos de descontração, brigas, falas altas, entrepostas e triviais, de modo a formar um conjunto representativo de um habitus de classe. 


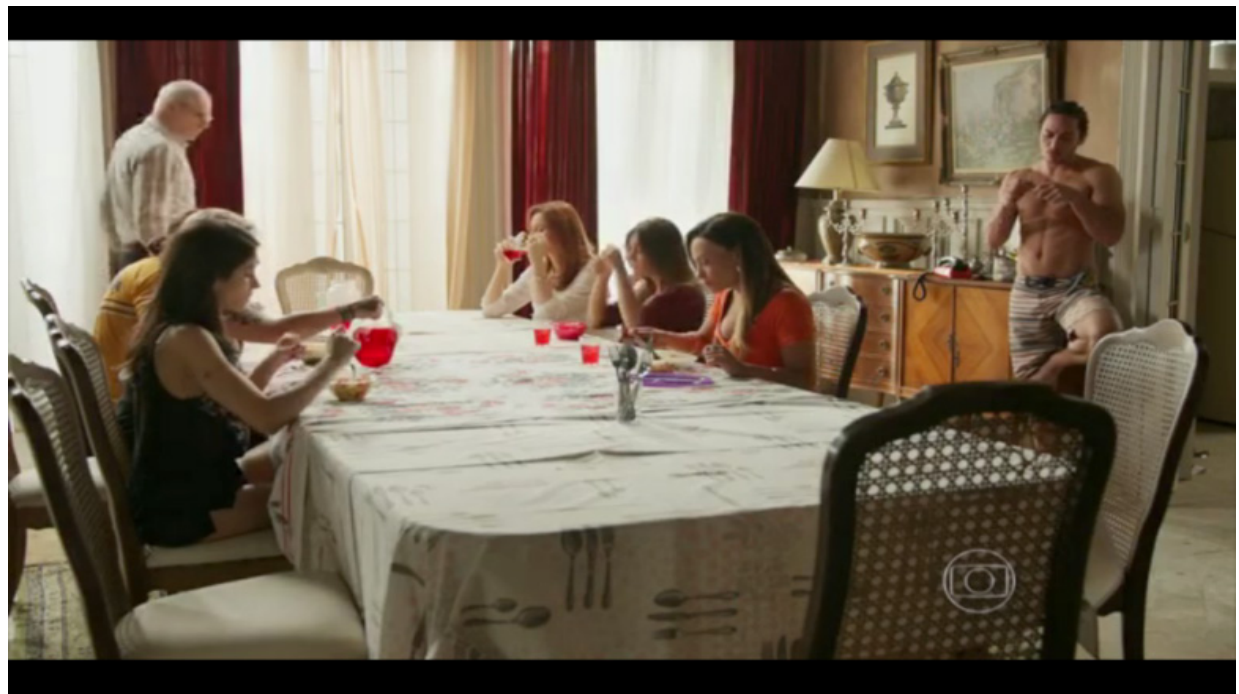

Figura 3: Refeição da família de Feliciano em A regra do jogo

Fonte: http://gshow.globo.com/novelas/a-regra-do-jogo/capitulo/ 2015/11/05/toia-surpreende-atena-com-romero.html\#video-4589475

Na família de Feliciano - que, ao contrário da família de Tufão, era rica e ficou pobre - são recorrentes conversas sobre economia de dinheiro na alimentação, e a falta de dinheiro para tanto, em tom cômico, enquanto comem em volta de uma mesa com pouca comida. "A insistência com que a cozinha e a alimentação marcam as telenovelas aponta para a cotidianidade da personagem e para a movimentação que em torno dela se cria para mantê-la 'viva e saudável'" (MOTTER, 2003, p. 114).

Também sobre realidade e cotidiano na ficção, Rancière (2010) aborda a oposição entre o efeito de realidade do romance realista e a lógica clássica de representação. De acordo com o teórico, no romance realista, há o real pelo real, o detalhe inútil, o ócio do cotidiano e o excesso, que indica a democracia do sensível.

Assim, o excesso realista não tem nada a ver com a ostentação burguesa da riqueza e da confiança no reino da Burguesia que alguns autores ali detectaram. O que está no seu coração é muito mais a confusão introduzida quando o excesso de paixão e o vazio do devaneio são apropriados pelas almas das classes baixas. (RANCIÈRE, 2010, p. 87) 
Segundo o autor, o efeito de realidade traz uma questão política do popular versus a elite da lógica clássica. Há uma ruptura na lógica de verossimilhança clássica, o que opõe a ação, na qual tudo está atrelado ao enredo, e a imagem, que traz justamente o excesso mencionado acima, um excesso democrático para o autor, e a ausência da lógica estrutural da narrativa, a quebra causal.

Rancière (2010) aclara que o excesso das palavras se dá pela entrada dos filhos de artesãos e camponeses no mundo da sensibilidade. É pertinente destacar a afirmação do autor de que "isso não é uma questão de personagens ficcionais. É uma questão de estrutura ficcional" (2010, p. 86).

Com foco maior nos personagens, Figueiredo (2012) traz questão semelhante ao tratar do $O$ homem ao lado, filme argentino sobre o convívio de dois vizinhos de classes sociais diferentes, com estéticas diversas - Vitor, de classe popular, e Leonardo, rico. Vitor apresenta um padrão estético que remete aos excessos, "submetendo a arte ao gosto da vida, das emoções mais imediatas" (2012, p. 112). Leonardo, por sua vez, designer famoso, possui um padrão estético clean, que se refere "ao lema do 'menos é mais', à ideia de que o objeto artístico deriva de uma construção racional que permite atingir a plena correspondência entre forma e função" (2012, p. 112).

Para obter mais luz do Sol, Vitor abre um buraco na parede de sua casa, o que expõe um dos cômodos de Leonardo ao olhar do vizinho. Esse fato representa, para Figueiredo, a questão da visibilidade, sobre quem tem o direito de ver e ser visto. A autora explica que a janela representa a divisão entre os territórios de diferentes classes sociais, nos confrontos existentes no espaço urbano.

Com relação à estética estrutural das cenas, é pertinente atentar para a quebra de estrutura da ação discutida por Rancière (2010). Na telenovela, dada a sua duração e quantidade de núcleos dramáticos, é natural que muitas das cenas não estejam totalmente relacionadas com o todo da ação. Porém, em Avenida Brasil, a quebra estrutural contribuiu para a caracterização dos núcleos populares. 
Em três cenas analisadas por Mauro (2014) - "Carminha reclama da comida de Janaína", "Jorginho não se lembra de Cadinho" e "Muricy reclama de filme indicado por Nina"4 - os nomes dados às cenas pelo site oficial da trama não se revelou importante para o que é assistido nos trechos. No primeiro fragmento analisado, a referência à Janaina, que consta no título, só é justificada no final da cena. Na segunda cena, Jorginho, destacado no cabeçalho, aparece poucas vezes. Sobressai um momento descontraído, barulhento e cômico entre os familiares que almoçam na casa de férias. No terceiro fragmento, mais encadeado com o título, a ênfase são os gostos culturais dos personagens.

Ou seja, os três trechos não desenvolvem grandes ações e não representam partes essenciais ao todo da telenovela, dialogando com o inútil, o ócio e o cotidiano comentados por Rancière (2010). O mesmo pode ser observado em alguns personagens de $A$ regra do jogo, como a família de Feliciano já mencionada, e nas cenas dos funkeiros Mc Merlô, Ninfa, Alisson e Andressa Turbinada.

Percebe-se, assim, uma estética do cotidiano em consonância com o que o sociólogo Bourdieu (2007) discute sobre o gosto de classe e com as táticas cotidianas abordadas por De Certeau (1998). De acordo com Bourdieu (2007) o gosto popular enxerga a estética por ela mesma, dissociada de uma função, de um conteúdo claro. A tendência é associar a arte com a própria vida, sem uma distinção entre forma e conteúdo. "Seja no teatro ou no cinema, o público popular diverte-se com as intrigas orientadas, do ponto de vista lógico e cronológico, para um happy end" (BOURDIEU, 2007, p. 35). 


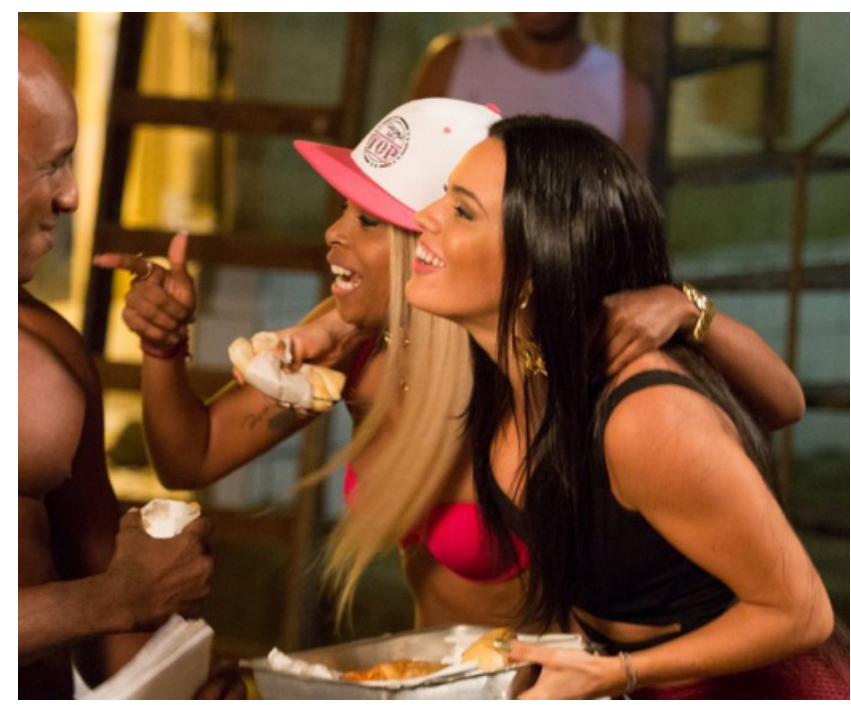

Figura 4: Ninfa e Alisson de $A$ regra do jogo

Fonte: http://gshow.globo.com/novelas/a-regra-do-jogo/vem-por-ai/ noticia/2015/10/ninfa-e-alisson-fazem-novos-planos-e-causam-revolta.html.

Ainda, as cenas de alvoroço dos núcleos populares, contendo assuntos banais; brigas, que provocam riso; comportamento relaxado dos personagens, como falar com a boca cheia, estar descalço com os pés em cima do sofá, cometer erros de português, usar palavras chulas, e rir alto e demasiadamente; trazem em evidência o corpo e suas necessidades primárias, em diálogo com os escritos de Bakhtin (1999) sobre Rabelais. Este escritor da Idade Média trazia em suas obras o realismo grotesco, caracterizado por uma gramática jocosa e pela transferência do elevado e o espiritual ao plano material e corporal; e a carnavalização, marcada como uma fuga da vida oficial, um mundo paralelo onde tudo era permitido.

Costuma-se assinalar a predominância excepcional que tem na obra de Rabelais, o princípio da vida material e corporal: imagens do corpo, da bebida, da comida, da satisfação das necessidades naturais, e da vida sexual. São imagens exageradas e hipertrofiadas. (BAKHTIN, 1999, p. 16).

Outro aspecto significante para a construção do discurso popular é a música. "Como o cinema é um meio audiovisual de níveis múltiplos, ele manipula não apenas o ponto de vista, mas também o que Michel Chion chama de 
'ponto de escuta' (point-d 'écoute)." (SHOHAT; STAM, 2006, p. 303). Os ritmos musicais que marcam os ambientes populares na telenovela, geralmente, são o samba, o forró e o funk. As músicas indicam o que o telespectador pode esperar de determinada cena. Por exemplo, os ritmos populares dançantes e com letras divertidas presentes em cenas com os personagens Suelen (Avenida Brasil), Adauto (Avenida Brasil), Muricy (Avenida Brasil), Oziel (A regra do jogo), Tina (A regra do jogo) sugerem e realçam a descontração e o humor das cenas e constituem também a caracterização do popular no contexto desses personagens.

É pertinente observar que determinados personagens se assemelham nas duas telenovelas e demonstram uma constante na representação dos tipos populares como cômicos, descontraídos, vestindo-se sensualmente no caso das mulheres, sem camisa no caso dos homens. A música contribui para essa caracterização direcionada à estereotipia. O mesmo ocorre nas cenas de alvoroço familiar, em Avenida Brasil, dos novos ricos, e em $A$ regra do jogo, dos ricos falidos.

Shohat e Stam (2006) elucidam que no discurso hegemônico os papéis considerados subalternos são vistos como sínteses de comunidades homogêneas, o que não ocorre com os papéis dos grupos dominantes que contam com representações diversas. "A questão crucial em torno dos estereótipos e distorções está relacionada ao fato de que grupos historicamente marginalizados não têm controle sobre sua própria representação" (SHOHAT; STAM, 2006, p. 270).

Porém, é preciso pontuar que existem outras representações do universo popular nas duas produções. As mocinhas e mocinhos da história costumam ser mais complexos, apresentam mais nuanças de caráter, como Nina e Jorginho em Avenida Brasil, e Tóia e Juliano em A regra do jogo. Nessa última trama, a personagem Domingas suscita discussões sociais em torno da violência doméstica que sofre por parte do marido. Destaca-se que em ambas as produções, mais da metade dos personagens pertencem às classes populares, o que oferece possibilidades de enfoques variados e mais complexos em alguns deles. 
Do ponto de vista dos estudos do imaginário, os personagens mais profundos poderiam se aproximar da concepção do arquétipo e o estereótipo seria "uma espécie de mito desmitologizado." (BARROS, 2009, p. 7). De acordo com Barros (2009), os estudos do imaginário mostram que a imagem nasce de um subsolo arquetípico, se torna consciente em símbolos, mitos e também estereótipos, em que os arquétipos conteúdos ainda não elaborados pela consciência humana e os mitos são as narrativas que organizam os símbolos.

Retomando a ideia da autora dos arquétipos como imagens universais, primordiais e inconscientes, tem-se uma concepção ampliada de imagem, como antecessora da linguagem, produto do imaginário. Pois, como expõe Durand (2001), a imagem é um símbolo, diferente do signo arbitrário da palavra. Ou seja, a dicotomia entre significante e significação não se dá no caso da imagem e imaginação.

Porém, de acordo com Durand (2001), o pensamento ocidental desvaloriza a imagem e a função da imaginação. Há uma minimização da imaginação e coisificação da imagem. O autor (2004) assinala o paradoxo da sociedade ocidental, calcada no racionalismo matemático, que exclui a imagem do pensamento teórico e epistemológico, mas que ao mesmo tempo está repleta de imagens propagadas pela mídia, por exemplo. O teórico defende a existência dos mitos fundadores nos relatos históricos ocidentais, pois o fato do imaginário ser posto de lado em nossa cultura não impediu o surgimento de mitos como Napoleão Bonaparte e Hitler, marcados pelo mito de Prometeu, da ascensão, do racionalismo e do positivismo. O mito, segundo o estudioso, reaparece pelos meios audiovisuais tecnológicos.

Durand propõe estudar o simbolismo imaginário por um trajeto antropológico que consiste, resumidamente na "incessante troca que existe no nível do imaginário entre as pulsões subjetivas e assimiladoras e as intimações objetivas que emanam do meio cósmico e social". (2001, p. 41). O estudioso toma como hipótese a relação entre os gestos do corpo, os centros nervosos e as representações simbólicas e realiza três classificações gestuais humanas 
originárias dos símbolos, são elas o gesto postural, a descida digestiva e os gestos da sexualidade. Todos eles são divididos em dois regimes: o diurno e o noturno. Por meio dessas concepções, ele propõe a mitocrítica e a mitoanálise.

O que nos interessa mais especificamente é a possibilidade de, ao ampliar a concepção de imagem considerando a sua natureza simbólica, poder estudar as especificidades do televisual em relação a outras mídias e ir além do entendimento da linguagem icônica televisual.

Afinal, as imagens nos permitem acessar instâncias humanas primordiais e universais? Como isso se daria no caso da estética popular das duas telenovelas? Qual o imaginário social existente a respeito da classe popular? De que forma esse imaginário se relaciona com a telenovela? Quais são os mitos latentes?

Acredita-se que o acréscimo dessa perspectiva do imaginário e da imagem - com os conceitos de mito, arquétipo e estereótipo - possa enriquecer as análises da estética popular em Avenida Brasil e $A$ regra do jogo, sem descartar a perspectiva sócio-histórica da análise, mas tornando possível extrapolá-la e ancorá-la a um âmbito mais abrangente e pouco explorado.

Talvez essa abordagem possibilite a conexão que Puñuela Cañizal (2013) encontrou na fotografia com as profundezas da faixa limite entre o círculo hermético e o círculo do aparecer de Eugênio Trías. "O círculo do aparecer corresponde ao domínio da linguagem, é um lugar em que se dá a experiência. O círculo hermético é uma matriz inacessível na qual se solidificam a origem e as primeiras causas." (2013, p. 99)

\section{Considerações finais}

Este artigo discutiu, de forma preliminar, o papel da imagem teleficcional na construção do discurso popular em João Emanuel Carneiro em parceria com Amora Mautner, nas telenovelas Avenida Brasil e A regra do jogo (2015). A materialidade da tela, em primeira instância, já designa um recorte entre o visível e o invisível. A divisão em capítulos e os ganchos finais com suspense fazem parte do gênero popular folhetinesco. Entretanto, se no folhetim em papel 
havia as letras grandes e espacejadas, a fragmentação das frases e da própria história para facilitar a leitura, hoje tem-se uma narrativa guiada pela câmera, o aparado em cujo lugar o telespectador se coloca onipresente.

Os hábitos cotidianos dos personagens, marcados pelo cenário doméstico, objetos decorativos, e figurino, por exemplo, permitem o reconhecimento e a intimidade com os personagens. Em Avenida Brasil e A regra do jogo, o cotidiano ganhou novos contornos na caracterização do popular, com diálogos mais informais, entrepostos e em voz alta; cenas triviais sem conexão com o todo, que quebram a verossimilhança clássica (RANCIÈRE, 2010); os excessos na decoração que remetem ao popular; ângulos de câmera diferenciados para um efeito maior de realidade, aproximando-se do popular, do natural; aproximação com o corpóreo; e com a estética das necessidades mais imediatas. Ademais, as músicas reforçam a representação popular voltada para o humor e para a descontração, em alguns personagens, e preparam o telespectador para o clima pretendido.

É válido um aprofundamento maior nesses aspectos, com um mapeamento dos personagens, das trilhas sonoras, para, além de uma análise mais aprofundada, ser possível visualizar de forma mais adequada os diferentes trabalhos envolvidos na telenovela, como o do figurinista, o iluminador, o produtor musical, entre outros. Esses aspectos fazem parte do processo, que é apagado, entre o momento de encontro da câmera/objeto e espectador/ aparato (XAVIER, 2003), mas que precisam ser abordados para dissolver a "fé na imagem" e ingressar nas estruturas televisuais propriamente ditas.

Ainda, pretendeu-se demonstrar com as pontuações sobre a imagem e o imaginário que o estudo da linguagem televisual permite extrapolar um recorte sócio-histórico, sem com isso contradizê-lo, com análises que considerem os símbolos, mitos e arquétipos. Há muito ainda que explorar sobre a linguagem televisual, e considera-se salutar que a análise discursiva se desprenda de uma concepção puramente verbal e se aventure por teorias que permitam um olhar mais complexo. 


\section{Referências}

BAKHTIN, M. A cultura popular na Idade Média e no Renascimento: o contexto de François Rabelais. São Paulo: Hucitec, 1999.

. Estética da criação verbal. São Paulo: Martins Fontes, 2003.

BARROS, A. T. M. P. A saia de Marilyn: do arquétipo ao estereótipo nas imagens midiáticas. E-Compós, Brasília, v. 12, n. 1, p. 1-17, jan./abr, 2009.

BENJAMIN, W. Paris, capital do século XIX. In: KOTHE, F. (Org.). Walter Benjamin. São Paulo: Ática, 1985. p. 32-43.

BOURDIEU, P. A distinção: crítica social do julgamento. São Paulo: Edusp; Porto Alegre: Zouk, 2007.

BRASIL. Secretaria de Assuntos Estratégicos. Vozes da classe média. Brasília, DF: SAE/PR; SECOM, 2012.

CERTEAU, M. A invenção do cotidiano: artes de fazer. Petrópolis: Vozes, 1998.

DURAND, G. As estruturas antropológicas do imaginário: introdução a arquetipologia geral. São Paulo: Martins Fontes, 2001.

O retorno do mito: introdução à mitologia. Mitos e sociedade. Famecos, Porto Alegre, n. 23, p. 7-22, abr. 2004.

FIGUEIREDO, C. Novo diccionário da língua portuguesa. 1913. Disponível em: <http://www.dicionario-aberto.net/dict.pdf>. Acesso em: 23 mar. 2016. 
FIGUEIREDO, V. L. F. A partilha do espaço urbano e a questão do outro próximo: repercussões no discurso teórico e na ficção cinematográfica. Galáxia, São Paulo, n. 24, p. 103-114, dez. 2012.

HAMBURGER, E. Diluindo fronteiras: a televisão e as novelas no cotidiano. In: SCHWARCZ, L. M. (Org.). História da vida privada no Brasil. São Paulo: Companhia das Letras, 1998. p. 439-487.

LOPES, M. I. V.; MUNGIOLI, M. C. P. Brasil: a telenovela como fenômeno midiático. In: LOPES, M. I. V.; OROZCO-GÓMEZ, G. (Coord.). Memória social e ficção televisiva em países ibero-americanos: anuário Obitel 2013. Porto Alegre: Sulina, 2013. p. 129-167.

MARTÍN-BARBERO, J. Dos meios às mediações: comunicação, cultura e hegemonia. Rio de Janeiro: UFRJ, 2009.

MAURO, R. Aspectos da midiatização do consumo e do sentido de classe social na telenovela: a representação da "nova classe C". Dissertação (Mestrado em Ciências da Comunicação) - Escola de Comunicações e Artes, Universidade de São Paulo, São Paulo, 2014.

MEYER, M. Folhetim: uma história. São Paulo: Companhia das Letras, 1996.

MOTTER, M. L. Fiç̧ão e realidade: a construção do cotidiano na telenovela. São Paulo: Alexa Cultural, 2003.

PEÑUELA CAÑIZAL, E. Enquadramentos ideológicos e escriturais em textos visuais. Matrizes, São Paulo, v. 7, n. 2, p. 95-111, jul./dez. 2013. 
RANCIÈRE, J. O efeito de realidade e a política da ficção. Novos Estudos Cebrap, São Paulo, n. 86, p. 75-80, mar. 2010.

RONSINI, V. V. M. A crença no mérito e a desigualdade: a recepção da telenovela do horário nobre. Porto Alegre: Sulina, 2012.

SANTAELLA, L. A teoria geral dos signos: como as linguagens significam as coisas. São Paulo: Cengage Learning, 2008.

SILVA, G.; SOARES, R. L. Para pensar a crítica de mídias. Famecos, Porto Alegre, v. 20 , n. 3, p. 820-839, set./dez. 2013.

SOARES, R. L. Telas e janelas, molduras das imagens. Significação, São Paulo, v. 28, n. 16, p. $31-44,2001$.

STAM, R.; SHOHAT, E. Crítica da imagem eurocêntrica: multiculturalismo e representação. São Paulo: Cosac Naify, 2006.

XAVIER, I. O olhar e a cena: melodrama, Hollywood, cinema novo, Nelson Rodrigues. São Paulo: Cosac Naify, 2003.

submetido em: 24 mar. 2016 | aprovado em: 12 mai. 2016 